\title{
スリットパターン化した CoFe 系高飽和磁化膜の磁気特性と異方性磁界制御 Magnetic Properties and Anisotropy Field of Slit-Patterned CoFe Films with High Saturation Magnetization
}

\author{
荒木 和幸・宗像 誠・並河 雅志・八木 正昭・島田 寛* \\ 崇城大学エネルギーエレクトロニクス研究所, 熊本市池田 4 22-1 ( ₹ 860-0082) \\ *東北大学多元物質科学研究所, 仙台市青葉区片平 2-1-1 ( ₹ 980-8577)
}

\author{
K. Araqui, M. Munakata, M. Namikawa, M. Yagi, and Y. Shimada* \\ Energy Electronics Laboratory, Sojo Univ., 4-22-1 Ikeda, Kumamoto 860-0082 \\ * Institute of Multidisciplinary Research for Advanced Materials, Tohoku University, 2-1-1 Katahira, Aoba-ku, Sendai 980-8577
}

In order to obtain magnetic thin film cores for MMIC (Monolithic Micro-wave Integrated Circuit) inductor, slit patterned CoFe thin films with high saturation magnetization more than $23 \mathrm{kG}$ was fabricated on glass substrate. Annealing effects on the magnetic properties of the film were investigated. The anisotropy field $H_{k}$ more than 200 Oe was induced together with soft magnetic properties corresponding to $\mathrm{GHz}$ frequency driving. For the much higher driving frequency range of $\mathrm{GHz}$, the $H_{k}$ is found to be controllable, according mainly to demagnetizing field estimated from geometries of the slit patterned film with the higher saturation magnetization.

Key words: magnetic thin film, high saturation magnetization, demagnetizing field, slit patterned films,

\section{1. はじめに}

無線LANやBluetoothに代表される高速，大容量通信機 器は, 現在1〜3 GHzで動作している.さらにこの動作周 波数は次世代のGHz帯集積回路の開発に向けて3〜 $6 \mathrm{GHz}$ に高周波化されつつある1),2) .

一方, 集積回路に用いる空芯インダクタの小型化が急 務の課題となっている . この課題解決法の一つとして , 薄膜磁心を適用して磁束を収束させることにより低面積 化する方法が提案され，これまでに薄膜磁心材料および インダクタデバイスの試作開発が行われている3)-5) .

しかし, 従来の磁心膜の場合, 次世代の動作周波数で は共鳴損失が大幅に増加するため, 弚の適用はほとんど 困難である .この問題克服のためには，(1)式に示すよう に磁心膜の飽和磁化 $4 \pi M_{s}$ および異方性磁界 $H_{k}$ を共に大 きくすることによって, 共鳴周波数

$$
f_{r}=\gamma \times\left(M_{s} H_{k} / \pi\right)^{1 / 2}
$$

を大幅に引き上げ, 共鳴損失を低減する必要がある．ここ で，Yはジャイロ磁気定数である.

$23 \mathrm{kG}$ 以上の高飽和磁化を示すbcc-CoFe合金膜は, 高 周波化および高透磁率化が要求される磁気へッドや磁心 への実用が期待され，低保磁力化や異方性磁界の制御の ための研究が多〈行われている5)-7). 特に次世代のGHz帯 高周波磁心については，200 Oe以上の異方性磁界を付与 できれば高飽和磁化を生かした低共鳴損失化と高透磁率 化が可能であると見込まれるが8)，これまでの報告では
100 Oe程度の異方性磁界しか得られていない．

本研究では, bcc-CoFe合金膜にスリット加工を施し， 高飽和磁化を反映させた大きな反磁界を誘導することに より，200 Oe以上の異方性磁界を得ることを試みた9). 兴の結果, 次世代のGHz磁心創出の端緒となる異方性磁 界制御の可能性を見出したので報告する．

\section{2. 実験方法}

製膜は，二元同時RFマグネトロンスパッタ法10)によ り, C0ターゲット(純度 99.99 at. \%, 直径 $100 \mathrm{~mm} \times$ $5 \mathrm{~mm}$ ), Feターゲット(純度 99.99 at. \%, 直径 $100 \mathrm{~mm}$ × $5 \mathrm{~mm}$ )を用いてAr雾囲気中で行った .この製膜法では， 円筒型電極の側面に基板が配置され，円筒の中心軸を回 転軸として基板が電極とともに回転する．上記の二種類 のターゲットはこの円筒電極の側面に対抗した配置をと り，各ターゲットからのスパッタ原子が円筒電極の高速 回転によって基板上に混合しながら堆積される.円筒電 極は原子一層分堆積する間に4回転(140 r.p.m.)以上回転 させた．膜の原子組成比は各ターゲットへの投入電力の 比率を変化させて調整し, エネルギー分散型X線分析装置 (EDS)を用いて分析した．製膜前の到達真空度は9 9 10-8 Torr以下とし，製膜時のAr圧力を 3 mTorr , 膜厚を $0.5 \mu$ $\mathrm{m}$ とした . 基板にはガラス(松波ガラス製 \#7059, 45 mm $\times 45 \mathrm{~mm} \times 1 \mathrm{~mm}$ )を用い，製膜中は水冷した．製膜後は， 3× 10-6 Torr以下の真空中で800 Oeの直流磁界を印加しな がら，200〜 $500{ }^{\circ} \mathrm{C} て ゙$ 回転磁界中または一方向磁界中で 80 分間熱処理した，一方向磁界中熱処理については容易 磁化軸方向に磁界を印加した。

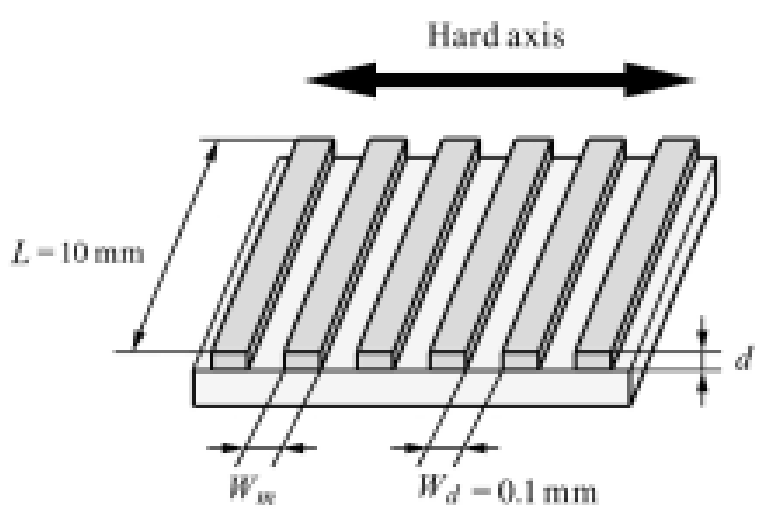

Fig.1 A schematic view of the slit patterned CoFe films. 
膜のスリット加工にはダイシングソー (Disco 社製， DAD 321) を用い, Fig. 1に示すようにスリットの長さ $L$ を10 mm , スリット幅 $W_{d}$ を0.1 mmに关れ光れ固定し， スリットの間隔を調整して磁性膜の幅 $W_{m}=1 \sim 0.075$ $\mathrm{mm} し, L \times W_{m}$ の短冊形状膜を作製した．また，葉 巻型回転楕円体近似で求められる反磁界より $H_{k}$ を計算し 測定により得られた $H_{k}$ と比較した。

\section{3. 実験結果}

\section{1 飽和磁化と Fe原子組成}

Fig. 2は, As-dep.状態, 熱処理温度 $T_{a}=400{ }^{\circ} \mathrm{C}$ 熱処 理後における膜および代表的なバルク状態の試料における 4ா $M_{s}$ とFe原子組成比 $X$ との関係を示す. 両者の膜ではX $=80 \sim 82$ at.\%において約23 kG以上の高飽和磁化が観測さ れ，熱処理後においても光の值にほとんど変化が見られな いことがわかる．このことは，As-dep . 状態で高飽和磁化 のCoFe単相が生成されており，少なくとも $T_{a}=400{ }^{\circ} \mathrm{C}$ では光の状態が保たれていると考えられる．バルク状態で は , $X=65$ at.\%で最大值4ா $M s=24.5 \mathrm{kG}$ 示し , $X=85$ at.\%において4ா $M s=23 \mathrm{kG}$ となるまでなだらかに減少す る結果が報告されている．また，これまでに報告された CoFe系のスパッタ膜についても,$X=66 〜 72$ at.\%におい て 4ா $M_{s}=24.0 〜 24.5$ kGが報告されているが11),12)，この 結果においては得られていない .

\section{2 保磁力, 異方性磁界の熱処理依存性}

\section{2.1 回転磁界中熱処理効果}

スリット加工前のAs-dep . 状態の膜に回転磁界中熱処理 を施し，光の効果について調べた . Fig. $3(\mathrm{a}),(\mathrm{b})$ は, 異方 性磁界 $H_{k}$, 困難磁化軸および容易磁化軸方向の保磁力 $H_{c h}$, $H_{c e}$ の熱処理温度 $T_{a}$ 依存性を午れ示す. As-dep. 状態 において $H_{k}=100 \mathrm{Oe}$ 顕著な一軸磁気異方性が基板の移動 方向に対して垂直に観測され，保磁力については $H_{c h}=15$ Oe , $H_{c e}=30$ Oeが得られている . $H_{k}$ についてはFig.3(a) の太線に示すように，同じ製膜条件下においても試料ごと にばらつきを示すが, 弚の容易磁化軸方向はスパッタ装置 の回転円筒アノードの回転方向と常に一致している .

$H_{k}$ は $T_{a}$ の増加に伴って単調に減少し, $T_{a}=350{ }^{\circ} \mathrm{C}$ 以上 ではほとんど消失して等方性を示すことが観測される．こ れに対応して, $H_{c h}$ およびH $H_{c e}$ はAs-dep. 状態から減少し，

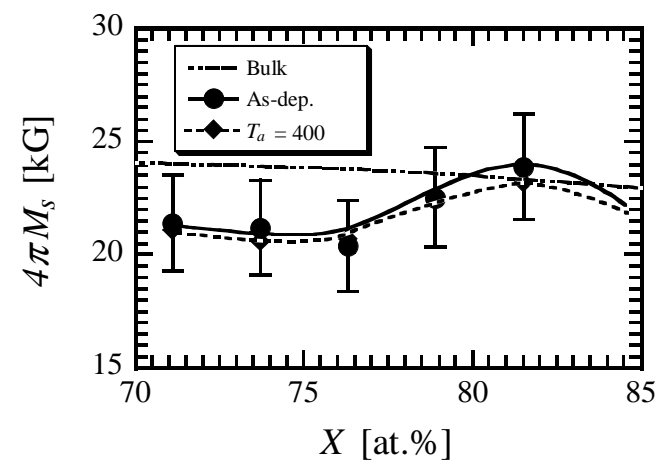

Fig.2 Fe at.\% $(X)$ dependence of saturation magnetization for the films in as-deposited state and after annealing at $400^{\circ} \mathrm{C}$.
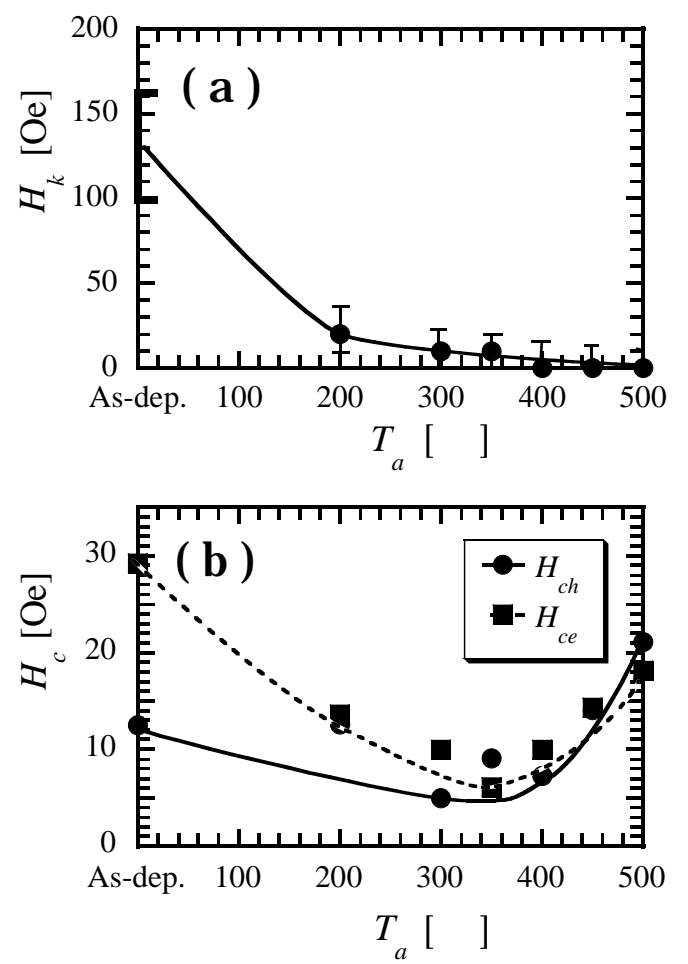

Fig. 3 Annealing temperature dependence of (a) $H_{k}$, (b) $H_{c h}$, and $H_{c e}$ with rotating-field annealing.

$T_{a}=350 \sim 400{ }^{\circ} \mathrm{C}$ で10 Oe以下の最小值をとる

このことから，10 Oe以下までの低保磁力化と磁気特性の 等方化が， $T_{a}=350$ ～ $400{ }^{\circ} \mathrm{C}$ 範囲で可能であることがわ かる.

\section{2.2 一方向磁界中熱処理効果}

Fig. 4 (a)，(b)は，スリット加工前の膜に一方向磁界中熱 処理を行ったときの $H_{k}$ および $H_{c h}, H_{c e}$ の $T_{a}$ 依存性を关れ 光れ示す. $H_{k}$ はFig. 3(a)と同樣に $T_{a}=200{ }^{\circ} \mathrm{C}$ までは単調 に減少してほとんど等方的な值を示すが， $T_{a}=200{ }^{\circ} \mathrm{C}$ 以 上では増加に転じ， $T_{a}=450{ }^{\circ} \mathrm{C}$ 付近では数10 Oe程度まで 増加する . $T_{a}=200{ }^{\circ} \mathrm{C} の H_{k}$ の減少は, 熱処理中の印加磁 界の有無に依存しないことから，磁界による誘導磁気異方 性ではなく，歪み，内部応力などの緩和に起因すると考え られる.一方， $T_{a}=200{ }^{\circ} \mathrm{C}$ 以上の $H_{k}$ の増加は, Fig.3(a)に 示した回転磁界中熱処理の場合は減少していることから， 磁界による誘導磁気異方性であると考えられる． $T_{a}=350$

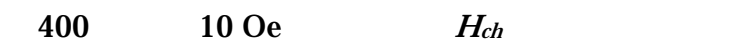

以上の結果， $T_{a}=300 \sim 400^{\circ} \mathrm{C}$ 範囲でHchを10 Oe以下に 保ちながら $H_{k}$ を20〜60 Oeの範囲で誘導できることがわか った .

\section{3 結晶構造}

Fig.5 は As-dep.状態, $T_{a}=350{ }^{\circ} \mathrm{Cおよび} T_{a}=400{ }^{\circ} \mathrm{C}$ の膜の XRD パターンを光れ午れ示す．ともに高飽和磁化 を示す bcc-CoFe 単相のピークが観測され，これらはこれ までに報告されている XRD パターンとよく一致している 10). Fig. 2 に示したように熱処理後も飽和磁化が一定であ ることに加え, ピーク位置やピーク強度比に変化がないこ とから，bcc-CoFe 単相はAs-dep.状態から形成され，熱処 

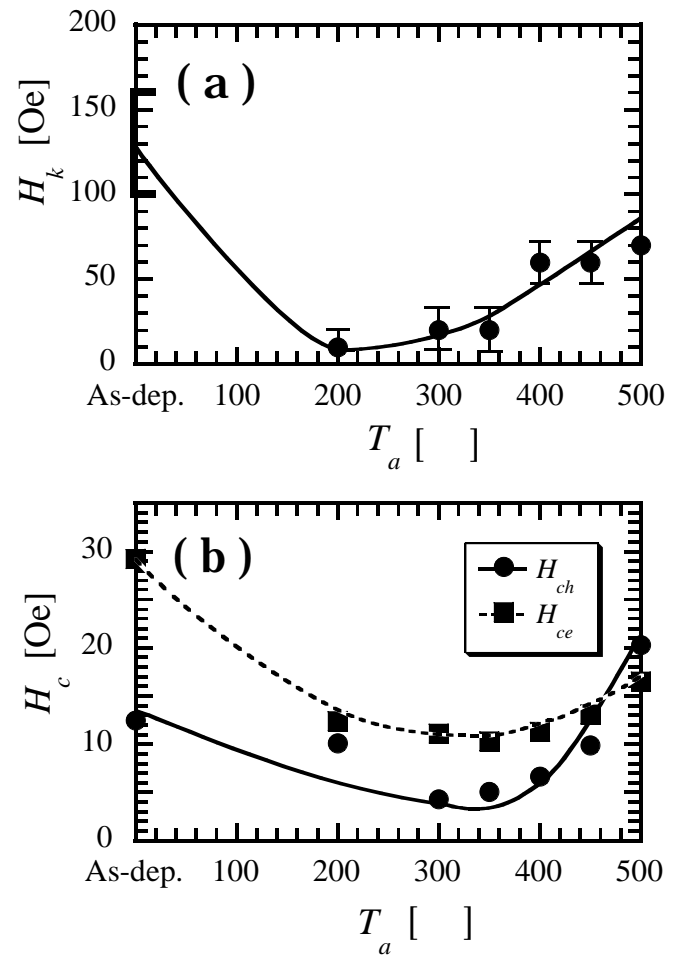

Fig. 4 Annealing temperature dependence of $(\mathrm{a}) H_{k}$, (b) $H_{c}$, and $H_{c e}$ with static field annealing.

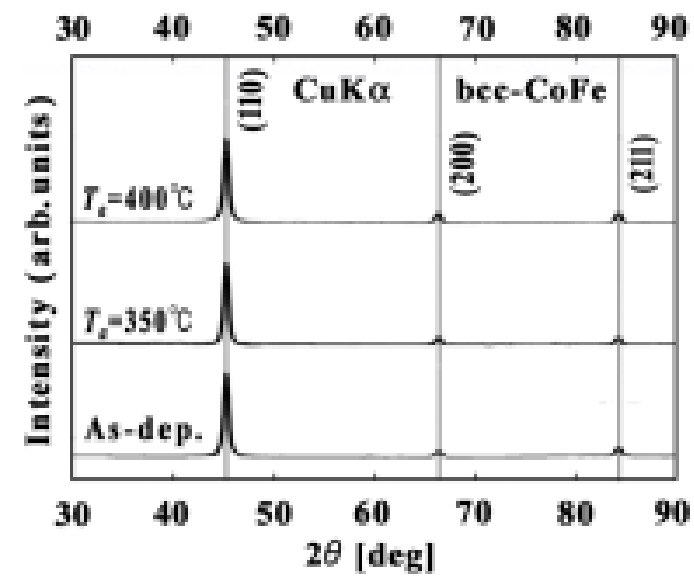

Fig.5 Annealing temperature dependence of XRD patterns of the film.

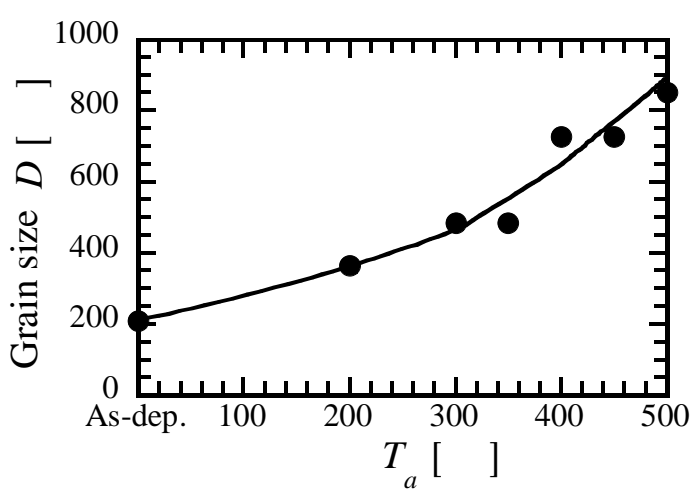

Fig. 6 Annealing temperature dependence of grain size.

理後においても同じ構造が保たれていると考えられる．ま た , これらのパターンの(110)ピークのロッキング曲線測定 の結果，特殊な配向はなく，ほとんど無配向でTaに依存 しないことが確認されている。

一方，ピークの半值幅は $T_{a}$ に依存し， $T_{a}$ の増加に対し て減少している.Fig.6 はScherrerの式13) を用いてピーク 半值幅から結晶子の大きさDを求めたものである.Dは As-dep.状態から $T_{a}=500{ }^{\circ} \mathrm{C}$ の範囲で, $200 \AA$ から $700 \AA$ まで単調に増加している. $T_{a}=400{ }^{\circ} \mathrm{C}$ 以上における $H_{c h}$ お よび $H_{c e}$ の増加は， $D$ の増加によると推察される ${ }^{15)}$.

\section{4 スリット加工膜の異方性磁界}

Fig. 2において飽和磁化が最大となる $X=79.6$ at.\%の膜 にスリット加工を施し，保磁力の減少と誘導磁気異方性の 付与をするため $T_{a}=400{ }^{\circ} \mathrm{C} て ゙$ 熱処理を行った . Fig. 7は， スリット加工した膜 (短冊形状膜) $の H_{k}$ と寸法比 $L / W_{m}$ $(L=10 \mathrm{~mm}$ : 固定)との関係を, 回転磁界中熱処理のみを 行った場合（の）および回転磁界中熱処理の後，一方向性 磁界中熱処理を行った場合（听よび回）について示す，

$W_{m}=0.5 \sim 1 \mathrm{~mm}\left(L / W_{m}=20 \sim 10\right)$ の範囲では, 回転 磁界中熱処理のみの場合は $H_{k}=0 \mathrm{Oe}$, さらに一方向性磁 界中熱処理を行った場合は $H_{k}=10 \sim 20$ Oeが光れ光れ観測 される.この範囲では形状異方性による反磁界は小さいの で，一方向性磁界により誘起された異方性磁界が出現して いると考えられる. $W_{m}=0.10 \mathrm{~mm}$ 以下 $\left(L / W_{m}=100\right.$ 以 上)では反磁界による $H_{k}$ 誘導され， $W_{m}=0.08 \mathrm{~mm}(L /$ $\left.W_{m}=133\right) て ゙ H_{k}=220 \sim 250$ Oeを示す. 一方向性磁界中 熱処理を行った場合の $H_{k}$ は，回転磁界中熱処理のみの $H_{k}$ に比べ，磁界により誘導された分だけ重畳的に大きくなっ ていると考えられる .

また， $W_{m}$ を円筒部の直径とした葉巻型回転楕円体近似 から計算した值 (図中実線) と比較したところ, 弚の変化 の傾向すなわち反磁界による $H_{k}$ の増加傾向はほぼ一致し ている. 計算値との差は, 近似に用いた葉巻型円筒の直径 $\left(W_{m}\right)$ が膜厚と大きく異なるためであり，より正確には有 限要素法などの磁界解析》が必要である .

以上の結果は, スリット加工膜の高飽和磁化に対応して 大きな反磁界15) か誘導されたことを示すと考えられる

一例として , Fig. 8 に $H_{k}=250$ Oeの膜(Fig.7の( 口)の 点)の $M-H$ 曲線を示す．明瞭な一軸磁気異方性が，スリッ 卜加工膜の長手方向が容易磁化軸と一致するように誘導さ

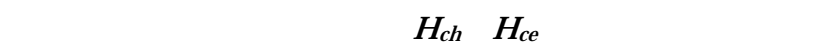

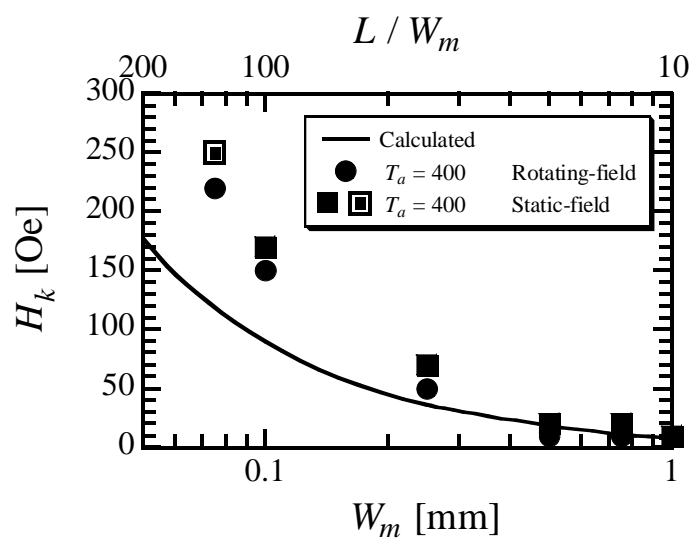

Fig.7 $W_{m}$ and rectangle ratio dependence of anisotropy field. 


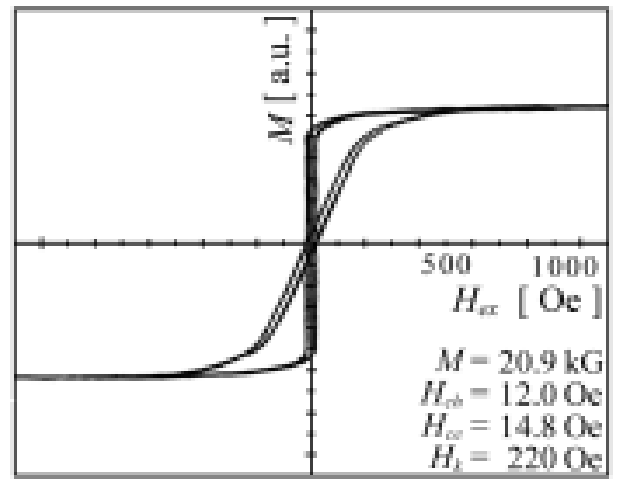

Fig. $8 M-H$ curve of slit patterned CoF e films after static field annealing.

によって10 Oe 程度の值が得られており，高周波において は十分に磁心特性を示し得る低い保磁力が得られている16)

以上に示した $H_{k}$ は，M-H曲線より求められた試 料全体の平均的な値であるが，実際の高周波特性に おいては初磁化範囲の微視的な $H_{k}$ の効果がより支配 的であり，微視的な $H_{k}$ の分散や磁区構造などの影響 があることが知られている17),18). $10 \mathrm{GHz}$ 程度の共鳴 周波数を得るには400〜 500 Oeの $H_{k}$ が必要であると 試算される ${ }^{8)}$ が, 実際に得られた $H_{k}$ よりさらに大き な值を得るには，磁区構造と高周波透磁率との関連 も詳しく検討する必要がある。

\section{4. まとめ}

回転円筒型二元同時マグネトロンスパッタ法により高 飽和磁化のCo-Fe膜を作製し，光の磁気特性を調べた結果， 以下の知見が得られた.

1) Fe原子組成比 80〜82 at. \%において，23 kG以上の 高飽和磁化を有するbcc-CoFe単相の結晶質膜が得られた この膜の結晶子の大きさは約600 ^̊であり，ほとんど無 配向であった .

2) 膜の保磁力および異方性磁界の熱処理効果を調べた 結果, 最適熱処理温度350〜 400 ${ }^{\circ} \mathrm{Cを}$ 見出した .これに よって回転磁界中においては10 Oe以下の保磁力で等方 性磁化膜が得られ，一方向磁界中では10 Oe以下の保磁 力と20〜数十 Oeの異方性磁界が誘導されることがわか った .

3) 形状比133 ( $\left.L / W_{m}=10 \mathrm{~mm} / 0.075 \mathrm{~mm}\right)$ のスリッ 卜加工膜において，250 Oeの異方性磁界が誘導され， 高飽和磁化によるより大きな反磁界がより大きな異方性 磁界を得るために有効であることがわかった .

これらの結果は, 高飽和磁化膜を用いれば，現状のス リット加工精度の範囲内で, さらに大きな異方性磁界 (400〜500 Oe)が得られる可能性を示すものであり，10
$\mathrm{GHz}$ 程度の共鳴周波数を得るための有効性を示唆してい ると考えられる .

謝辞 製膜装置の部品設計製作の継続的な技術協力を頂 いた斎藤マシン工業(株)社長 斎藤貞治氏，専務取締役阿 部光成氏に深く謝意を表する．また，結晶構造の解析に おいて多大な助言をいただいた(株)リガクの三浦双葉氏，な らびに製膜や測定に逐次協力を頂いた学生の青木大生氏， 清嶋輝彦氏に深く謝意を表する．

本研究の一部は, 文部科学省平成15年科学研究費基盤 研究(C)(2) (No. 15560285)の援助によった .

\section{References}

1) M. Ymaguchi: IEEJ J., 123, 11, 716 (2003).

2) M. Yamaguchi and K. I. Arai: J. Magn. Soc. J pn. , 25, 59 (2001).

3) Teak-Soo Kim, K. Suezawa, M. Yamaguchi, K. I. Arai, Y. Shimada and Chong-Oh Kim: IEEE Trans. Magn , 37, 4, 2255 (2001).

4) T. Kokai, T. Sato, K. Yamasawa, H. Karasawa and T. Sakuma: J. Magn. Soc. J pn., 26, 4, 484 (2003).

5) K. Ikeda, K. Kobayashi, K. Ohta, R. Kondo, T. Suzuki and M. Fujimoto: IEEE Trans. Magn., 39, 5, 3057 (2003).

6) K. Shintaku, K. Yamkawa and K. Ouchi H. Fujimoto: $J$. Magn. Soc. J pn., 27, 4, 367 (2003).

7) G. S. D. Beach, T. J . Silva, F. T. Paker, D. J . Smith and A. E. Berkowitz: In Proc. of Intermag Conf., Boston, USA, Mar., FC-02 (2003)

8) S. I keda, K. H. Kim, M. Yamaguchi, K. I. Arai, H. Nagura, S. Ohnuma and Y. Shimada: J. Magn. Soc. J pn., 27, 4, 594 (2003).

9) K. Suezawa, Y. Takahashi, M. Yamaguchi, K. I. Arai, Y. Shimada, W. D. Li, S. Tanabe and K. I to: J. Magn. Soc. J pn., 23, 4-2, 1637 (1999).

10) M. Namikawa, M. Munakata, M. Yagi, M. Motoyama, Y. Shimada, S. Yabukami, M. Yamaguchi and K. I. Arai: J. Magn. Soc. J pn., 27, 4, 371 (2003).

11) K. Shintaku, K. Yamakawa, and K. Ouchi: J. Magn. Soc. Jpn., 27, 4, 367 (2003).

12) H. Tomita, A. Sawabe, T. Sato, and T. Mizoguchi: J pn. J. Appl. Phys., 34, 1851 (1995).

13) B. D. Cullity, Elements of X-Ray diffraction, Massachusetts: Addition-Wesley Pub, Co, 94 (1977).

14) G. Herzer: IEEE Trans. Magn., MAG-26, 1397(1990).

15) S. Chikazumi: Physics of ferromagnetism, Tokyo, Syokabo, 11 (1979).

16) M. Munakata, M. Motoyama, M. Yagi, Y. Shimada, M. Baba, M. Yamaguchi and K. I. Arai: J. Magn. Soc. J pn., 25, 4, 919 (2001).

17) M. Munakata, M. Yagi, M. Motoyama, Y. Shimada, M. Baba, M.Yamaguchi and K. I. Arai: IEEE Trans. Magn., 37, 4, 2258 (2001).

18) H. Kikuchi, N, Ajiro, M. Yamaguchi, K. I. Arai and M. Takezawa: J. Magn. Soc. J pn., 25, 4-2, 975 (2001).

2004 年 3 月 10 日受理, 2004 年 7 月 20 日採録 